\title{
POR LAS VEREDAS DEL NEOFEMINISMO DURANTE MEDIO SIGLO*
}

HALF A CENTURY ALONG NEOFEMINIST BYWAYS

\author{
Eli Bartra**
}

\section{RESUMEN}

En este texto hago un recorrido, desde lo personal, sobre el neofeminismo desde la década de 1970 y su entrada en la academia. Se abordan los estudios de la mujer y feministas en la universidad, así como la investigación y la epistemología feministas. Se subraya la importancia de la inverstigación generizada en el campo de las ciencias sociales y el estudio de las artes visuales; en particular enfatizo en la autoetnografía para ilustrar una forma posible de estudio del arte popular. También se considera el activismo feminista en y desde la academia.

Palabras clave: Neofeminismo, artes visuales, epistemología, academia, activismo.

\section{ABSTRACT}

In this text, I carry out an overview, from a personal perspective, on neofeminism since the I970s, and its entry into academia. Women's and feminist studies are considered, as are feminist research and epistemology. I emphasize the importance of genderized research in the social sciences and the visual arts, and focus particularly on autoethnography to illustrate one possible form of studying folk art. Moreover, I examine feminist activism within and from the university.

Keywords: neofeminism, visual arts, epistemology, academia, activism.

Recibido 19 de marzo de 2021 y aceptado I9 de mayo de 2021

* La versión original de este texto se escribió en el formato de citación Harvard, ya que la postura política feminista de la autora plantea que el formato APA -utilizado como criterio editorial de esta revista invisibiliza a las mujeres citadas al colocar sólo la inicial de su nombre dejando el apellido completo sin un género específico.

"Profesora Distinguida, Universidad Autónoma Metropolitana UnidadXochimilco.<elibartra@correo.xoc.uam.mx>. 


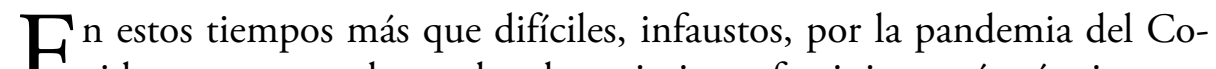
Evid-19 que azota al mundo, el movimiento feminista está más vivo que nunca. Lo que está sucediendo hoy es lo que imaginábamos que sucedería, pero pensábamos que sería mucho antes. Las mujeres del movimiento neofeminista de los setenta teníamos una visión inmediatista: la revolución socialista era para el día siguiente y la revolución feminista también. Las masas feministas en la calle no se vieron en México durante el siglo pasado, eso solo llegó en esta segunda década del siglo Xxi. Ya en los ochenta nos percatamos qué difícil resultaba imaginar que esto sucedería y fue cuando algunas emprendimos la tarea de introducir el feminismo en la academia. Pensamos que las multitudes conformando un movimiento no las íbamos a ver pronto y decidimos, además - aunque no era algo meditado y concientemente articulado-, volcar el activismo hacia la academia. Es preciso decir que al principio no estábamos seguras de que la vía de la institucionalización fuera pertinente. Porque de eso se ha tratado, ni duda cabe, el feminismo en la academia se ha institucionalizado. Ello ha acarreado ventajas y desventajas. En cuanto a lo primero, ha sido una manera afortunada de transmitir el pensamiento feminista y formar a mujeres ( $\mathrm{y}$ a algunos hombres) para llevar a cabo investigación, o laborar en dependencias gubernamentales o no gubernamentales en favor de las mujeres y a legitimar el feminismo. También es la vía para formar a nuevas docentes en este campo y contribuir así a la expansión de una conciencia crítica feminista. Y, evidentemente, nuevas activistas.

Una parte complicada de la institucionalización, aparte de que no se puede ser demasiado radical porque se es vituperado y censurado, es que en ese proceso se pierde, obviamente, autonomía. Se está a merced de la normatividad de la institución y, por descontado, del Consejo Nacional de Ciencia y Tecnología (Conacyt).

\section{EN LAS AULAS}

La cantidad de mujeres que ha entrado en las instituciones de educación superior se ha incrementado año con año; comparada con la de hace un siglo resulta astronómica. Examinemos cifras muy simples de una universidad 
como la UAM que en 1999 tenía apenas veinticinco ańos de existencia; en 1974 en la UAM se recibieron 1679 alumnos y 556 alumnas. En 1998 se aceptaron de nuevo ingreso 3260 alumnos y 2550 alumnas. Es decir, que en 1974 se aceptó el $24.87 \%$ de mujeres y en 1998 ya era el 43.88 por ciento.

En 20I9, en toda la UAM había en licenciatura 22290 mujeres y 22798 hombres; en posgrado eran I89I mujeres y 2003 hombres, en total 24 I8I mujeres y 248 or hombres. En 2019 de nuevo ingreso hubo 5407 (49.51\%)

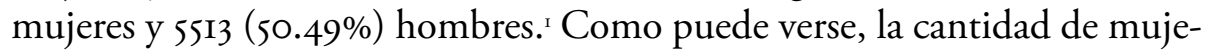
res ha subido enormemente hasta llegar casi a la paridad. Esto es así en una universidad pública relativamente nueva comparada con otras y en ciertas cuestiones se puede decir que de vanguardia.

Y solamente para mencionar los cargos más importantes de la universidad, las rectorías, hay que decir que nunca ha habido una rectora general (tampoco en la Unam). Y en cuanto a las rectorías de unidad, en resumen, ha habido 7 mujeres (I5.2\%) y 39 hombres (84.8). ${ }^{2}$

Ahora bien, para continuar con los botones de muestra en cifras, que a menudo son elocuentes, la UAM había nombrado en 25 ańos de vida a 17 profesores distinguidos, pero ni una sola mujer. En 2O2I se han nombrado 84 profesores/as distinguidos/as, 63 hombres y 2 I mujeres. En cuanto a profesores/as eméritos/as, hasta el presente ha habido I2, de los cuales 2 son mujeres.

En lo que a mí corresponde, en los setenta pasé como maestra por la Escuela Nacional de Antropología e Historia en donde los estudiantes, pero también algunas estudiantes, se doblaban de la risa cuando les anunciaba que íbamos a ver cosas sobre «la condición de la mujer», porque así se decía. A principios de la década de los ochenta, en que el movimiento neofeminista se volcó hacia las llamadas clases populares, en la academia -desde las ciencias sociales y las humanidades- abrimos en la Univeridad Autónoma Metropolitana-Xochimilco (UAM-X) el área de investigación «Mujer, identidad y poder». Fue el primer programa de este tipo en el país y sigue funcionando.

I UAM (2019). Anuario Estadistico. <https://transparencia.uam.mx/inforganos/ anuarios/anuario2019/anuario_estadistico2019.pdf $>$.

${ }^{2}$ UAM (20I8). Rectores de la Unidad Iztapalapa. UAM. <https://www.uam.mx/sah/pre-pa/ temao4/gal-rizt.html>. 
Cuando daba clases en aquella primera época sentía una apabullante esquizofrenia: por un lado, enseñaba historia de México o historia de las grandes revoluciones del mundo, desde una perspectiva totalmente androcéntrica y, en el mejor de los casos, la salpicaba de alguna idea feminista o de algún texto sobre mujeres y, por otro lado, seguía en el activismo feminista. He ahí a lo que llamo esquizofrenia, metafóricamente.

Además, imposible decir al estudiantado que yo era feminista porque no lo entendían. Eran los tiempos en que lo único que se pensaba era que estábamos contra los hombres y esto sigue vigente. Con ello se daba que era feminista de clóset. Sin embargo, desde ese núcleo de investigación creado, seguimos colectivamente con la idea de desarrollar los estudios de posgrado sobre las mujeres. Empezamos picando piedra, poco a poco. Primero un curso de Actualización en un año, mientras nos aprobaban el curso de Especialización con valor crediticio. Ya en 1999 abrimos la Maestría en Estudios de la Mujer y en 2017 el Doctorado en Estudios Feministas. Entre un programa y otro nos arrimamos, cual limosneras, al Doctorado en Ciencias Sociales de la misma UAM-X. Ninguna de las áreas de concentración ya creadas nos quería ahí. Hasta que hubo una que nos aceptó como una línea. Ahí estuvimos hasta que creamos un área de consolidación llamada Mujer y relaciones de género. Estuvimos is años hasta que, hartas de la miseria y la misoginia interna, decidimos formar el Doctorado en Estudios Feministas. Han sido muchos años de bregar y finalmente nos hemos consolidado en la academia, pero las batallas no han terminado, pues hay mucho por hacer $y$ por modificar todavía.

Quisiera subrayar que así como otros programas se nombraron desde un inicio o cambiaron muy pronto sus nombres de mujer a género, nosotras quisimos que desde un principio fueran estudios feministas, pero ni siquiera nos atrevimos a proponelo porque sabíamos de sobras que no iba a pasar. Por tanto, lo denominamos estudios de la mujer (en singular) porque así se usaba. Más de treinta años después ya pudimos ponerle Doctorado en Estudios Feministas no sin tener que justificarlo una y otra vez, pero fue aprobado. Nunca, nunca quise que se denominaran estudios de género, pero en la academia -ya lo sabemos- es más elegante decir de género que de la mujer o mujeres. Y así lo usan todo el tiempo al referirse a nuestros programas. No se trata simplemente de nombres sin importancia, pienso que es muy 
significativa la denominación. Mujer, mujeres y feminismo son conceptos que se refieren a sujetos devaluados, subalternos, y a su lucha. Género alude a todos los sujetos generizados y no solo a las mujeres.

Ahora bien, aunque fue una decisión nuestra la de abrir posgrados en los campos de las ciencias sociales y las humanidades y no estudios de licenciatura, pienso ahora que eso sería necesario. Si alguna de nosotras pasa por ahí, por el primer módulo de la universidad o por Tronco Divisional de Sociales, podemos modificar los contenidos y hacerlos menos sexistas. $\mathrm{O}$ si acaso se imparte algún módulo en una licenciatura. Pero no pasan de ser parches efímeros. Es decir, docencia con contenidos feministas o no sexistas solamente se da cuando las académicas interesadas en la temática estamos de docentes e impartimos los programas diseñados por nosotras. Ocupamos especies de nichos temporales. Pero, fuera de esos espacios, las ciencias sociales, en general, se imparten en casi todas partes tan androcéntricas como antaño. Los docentes no tienen el menor interés en enseñar ciencias sociales no sexistas. Las docentes, solamente si tienen determinada conciencia feminista, lo hacen o lo intentan hacer. Pero esta ha sido una ardua batalla que no se ha ganado todavía ni en la UAM ni en ninguna otra universidad mexicana.

Es relevante señalar que si hace 40 años el estudiantado se mofaba al escuchar hablar en un aula de «la condición de la mujer», hoy día quienes apenas están entrando en la universidad ya tienen cierta conciencia crítica y preguntan que cómo deberían de utilizar un lenguaje incluyente, que si @, e, x. Esto se encuentra a una gran distancia de los primeros años del neofeminismo. El nivel de información e incluso de conciencia que tienen hoy día algunas chicas y chicos jóvenes es asombroso.

Sin embargo, en la medida en que se avanza en algunas cuestiones, otras siguen impertérritas o peor, es el caso del sexismo cotidiano de docentes a alumnas y entre estudiantes:

Las prácticas docentes machistas muchas veces son ocultadas por los propios estudiantes, por temor a represalias. De igual manera, esto se repite en las relaciones entre los mismos alumnos y alumnas, sobre todo cuando surgen voces explícitas que buscar apelar y revertir las actitudes patriarcales universitarias. El sexismo de los profesores valida e incentiva las prácticas discriminatorias de los estudiantes, en tanto son figuras de 
autoridad que ironizan y ridiculizan no solo a las mujeres, sino que a las demandas feministas en su conjunto [...] La violencia se vuelve explícita, invisibilizada en humor y sarcasmo (Follegati, 2016: I24-I25).

Supe recientemente de un profesor que cuando una estudiante quiso cargar su silla para moverla de lugar le dijo que uno de los muchachos lo hiciera. Ella le contestó que podía sola, a lo cual el profesor -con sorna- replicó: «¡no serás una de esas feminazis!» Así se refieren también a las profesoras feministas de diversas universidades.

Este concepto, junto con los feminicidios, conforman dos de las embestidas de la revancha sexista, machista y misógina frente al avance del feminismo.

Si bien, como estoy señalando, hemos logrado consolidar los estudios de la mujer y feministas en la UAM, preciso es señalar que en lo que más se ha aportado es en la investigación. De hecho, eso es cierto para toda América Latina y el Caribe. Sin embargo, escasas distinciones y premios recibimos. No es nunca del agrado de jurados calificadores el trabajo de investigación feminista. Todavía se siguen asustando demasiado y, lo principal, lo consideran poco relevante.

Como conclusión de sus estudios de licenciatura, de maestría o de doctorado, el estudiantado debe llevar a cabo una investigación: las tesis. Como nuestra injerencia en las diversas licenciaturas de ciencias sociales es limitada, limitados son también los trabajos de tesis que tienen que ver con el feminismo. Pero los hay y cada vez más. De hecho, como en las respectivas carreras son tan rotundamente androcéntricos, con pocas excepciones, las alumnas nos vienen a buscar para solicitar nuestra ayuda cuando quieren llevar a cabo trabajos de tesis considerando la división genérica. Además, como digo, van en aumento los trabajos que se refieren, por ejemplo, a la violencia hacia las mujeres, uno de los temas más abordados por las estudiantes en todas las universidades. 


\section{INVESTIGACIÓN FEMINISTA EN CIENCIAS SOCIALES}

Desde la década de los setenta empecé a hacer investigación sobre mujeres, género o feminista en el terreno de las artes visuales. Lo que más me ha interesado es estudiar el quehacer de las mujeres en el arte popular (que no en las artesanías) en México y en otras latitudes. Pienso que poco se ha desarrollado ese campo en cualquier parte del mundo; en buena medida, de ahí mi particular interés. Evidentemente, al vivir en México las investigaciones las he realizado sobre todo aquí. Pero al haber tenido la fortuna de contar con periodos sabáticos y haber sido invitada para ir a otras universidades, aproveché para incursionar en el arte popular y las relaciones de género en otros países como Brasil, Japón y Nueva Zelanda, así como en Cataluña.

Aunque me haya, digamos, centrado en el arte popular, esta no ha sido mi única inclinación. A decir verdad, no he dejado de incursionar asimismo en la fotografía, el cine y en las artes plásticas. Lo que sucede es que, a diferencia del caso del arte popular, esas prácticas artísticas han sido bastante más contempladas desde una mirada feminista. De cualquier manera, esto no me ha detenido, pues pienso que es muchísimo lo que falta por hacer para enmendar el sesgo androcéntrico y excluyente en las artes. También las otras investigaciones en el campo de las artes (aparte del arte popular) las he realizado, fundamentalmente, sobre México.

Pienso que las prácticas artísticas, sobre todo las visuales, han sido y son factores cruciales para moldear conciencias, mentalidades. Los poderes siempre han utilizado las expresiones artísticas para cimentar y perpetuar sus creencias. Así, por ejemplo, el arte sacro de la Edad Media y el Renacimiento en Occidente (pero que dura hasta el siglo xx) servía para conservar el catolicismo, e incluso los desnudos se vieron insertos alegóricamente en la imaginería mítico-religiosa. Las artes visuales, en términos generales, han sido siempre importantes para perpetuar el sexismo y la misoginia en tanto en cuanto a la escasa posibilidad que han tenido las mujeres de acceder a las prácticas en igualdad de condiciones, como a la equitativa distribución y consumo de ellas. Pero, también en lo referente a la representación de los géneros y los roles impuestos socialmente. La visión que se obtiene de la relación entre los géneros en las distintas artes ha sido y es profundamente sexista. Por ello, resulta nodal, en primera instancia, generizar el campo; 
esto es, buscar la presencia y la ausencia de mujeres, por ejemplo, a lo largo de todo el proceso artístico popular. Al mismo tiempo, o después, en una segunda instancia, se lleva a cabo la exploración detenida y minuciosa de esas prácticas específicas de las mujeres y se trata de conocer cuál es su visión del mundo y, específicamente, su percepción de los géneros.

Dentro del pensamiento feminista siempre ha habido distintas corrientes y posiciones, algunas de ellas incluso un tanto antagónicas. Eso no es nuevo, no es del presente y no es privativo del feminismo. Lo que es distinto es que en la época actual se quiere subrayar con la utilización del plural, los feminismos. En décadas pasadas se alineaban en dos grandes grupos: las feministas de la igualdad y las de la diferencia. Pienso que eso fue bastante aberrante, pues no existe ninguna de las dos en estado puro y, generalmente, se hallan un tanto combinadas. En mi caso, pienso que en algunas cosas es preciso buscar la igualdad y en otras la diferencia. Igualdad de derechos sociales, políticos, laborales, pero no a pie juntillas, pues las mujeres, por serlo, requieren de tiempos especiales en los empleos para el parto y amamantar. Igualdad, pero contemplando las diferencias o llamémosle equidad. Sin embargo, para conocer los múltiples y diversos quehaceres de las mujeres a lo largo de la historia es preciso escudriñar y analizar las diferencias de género. De la misma manera que no podemos hablar dentro de las ciencias sociales o las humanidades del ser humano en general (excepto en un nivel de abstracción), es imperioso contemplar las similitudes y las diferencias entre hombres, mujeres, trans y demás. En el campo de las prácticas artísticas no podemos hablar del arte en general, sino de las diferentes prácticas y creatividades de los distintos géneros y sexualidades. Las artes no son ni neutras ni universales ni eternas. Quienes las practican tienen género, tienen edad, tienen etnia, racialización, sexualidad...

Preciso es decir que la visión feminista de la realidad y, por ende, la construcción del conocimiento desde un punto de vista - por lo menosno sexista se ha dado principalmente dentro de las ciencias sociales y las humanidades. Las primeras en donde se introdujo esta mirada fueron la antropología y la historia. Hoy prácticamente todas las disciplinas se han visto ya impregnadas por el feminismo. Unas más y otras menos. El campo de la sociología y la antropología del arte ya se ha beneficiado de un aire fresco proveniente del pensamiento y la investigación no androcéntrica. $\mathrm{Mi}$ 
trabajo se puede inscribir, a menudo, en la antropología del arte y también de la autoetnografía cuando me aboco al estudio del arte popular y he querido contribuir a la construcción de investigación no androcéntrica. Trabajo también desde el terreno de la estética (emparentado con la sociología del arte). Las artes van siendo cada vez más, lentamente, contempladas desde el feminismo y es así como se ha rescatado de la invisibilización a cientos de mujeres artistas del pasado. Además, se ha logrado que cada vez más mujeres entren en los circuitos de consumo. Pero importante resulta que en muchas partes del mundo lo que se están dando son prácticas artísticas no solamente de mujeres, sino feministas.

Ahora bien, voy a hablar un poco del campo de la autoetnografía puesto que me he referido a ello. No hay que confundir -se ha dicho mucho yala autobiografía con la autoetnografía, pero es sumamente común hacerlo. Esta nueva «forma narrativa de generación de conocimientos», como la llama Mercedes Blanco, y de comunicación de los mismos, quizá no sea tan nueva como se piensa. Lo nuevo, con certeza, es la reflexión sobre ello, la conceptualización y la forma de abordar la cuestión. (Blanco, 20I2: 53).

La autobiografía es la narración del transcurso de una vida humana pasada por el tamiz de la persona autobiografiada, cosa que la biografía no tiene. En ese sentido, la autobiografía sería más subjetiva, quizá, que la biografía, aunque ambas lo son inevitablemente.

Si la etnografía es el estudio, la descripción, la narración, de algún grupo o comunidad y sus quehaceres culturales, la autoetnografía implica que el sujeto que investiga se inmiscuye deliberadamente en la investigación. Se describe un proceso o una cultura explícitamente desde la visión de quien investiga y se relata esa experiencia. Sin embargo, muy a menudo encontramos que una supuesta autoetnografía inicia contando la vida del sujeto investigador desde la infancia, pasando por la adolescencia y demás historias bien personales que ni al caso vienen.

Para una autoetnografía feminista en este campo del arte popular se busca la visibilización de las mujeres y su trabajo y se tiene siempre presente la idea de cambio de sus condiciones de existencia; es decir, una investigación feminista se desarrolla con una metodología también feminista y tiene como objetivo último la transformación de las situaciones de desigualdad social entre los géneros. Al mismo tiempo, se contemplan los cambios en la 
investigadora en contacto con las mujeres investigadas y su arte. Al colocar a las mujeres en el centro y marginar, ni que sea momentáneamente, a los hombres de los micrófonos, se produce un cierto empoderamiento de las artesanas.

Una de las grandes diferencias entre la etnografía tradicional y la autoetnografía es que se tiende al estudio de determinados grupos o procesos dentro de la propia cultura, la propia clase social, el mismo género y a veces el mismo grupo etario. Otro aspecto que la distingue es, sin duda, el lenguaje, la exposición, la narrativa. De manera consciente se intenta romper con la fealdad de la escritura académica tradicional, mayestática (que es dizque incluyente de la persona o personas que investigan y de quien recibe), y se emplea un lenguaje más fluido, más bello o se utilizan los medios audiovisuales. De acuerdo nuevamente con Blanco, en los años noventa del siglo pasado «se le da aún más importancia a los aspectos literarios y retóricos, de tal suerte que se habla de un 'giro narrativo'" (Blanco, 2012).

El hecho de que la autoetnografía se escriba en primera persona es seguramente por influencia del neofeminismo que utilizó fuertemente el yo tanto como el nosotras, y descartó el nosotros que ha sido tan común en las ciencias sociales todas.

Mercedes Blanco define a través de diversos autores y autoras lo que debe entenderse por autoetnografía y dice, en síntesis, que se trata de la investigación y la escritura que conecta lo personal con lo cultural. ${ }^{3}$

Metodológicamente presenta sus complejidades, ya que de acuerdo con Alfredo Gaitán (citado por Mercedes Blanco) se «explora el uso de la primera persona al escribir, la apropiación de modos literarios con fines utilitarios y [se enfrentan] las complicaciones de estar ubicado dentro de lo que uno está estudiando. (Gaitán, 2000: I)». (Blanco, 2012: 55). En efecto, no resulta fácil separar la vivencia propia de las experiencias de las personas investigadas y sus quehaceres, las voces se pueden fácilmente confundir. Pero me parece

\footnotetext{
${ }^{3}$ «Carolyn Ellis aclara su significado: 'La autoetnografía es un género de escritura e investigación autobiográfico que [...] conecta lo personal con lo cultural' (2003: 209). Richardson coincide con Ellis al puntualizar: 'Las autoetnografías son altamente personalizadas, textos reveladores en los cuales los autores cuentan relatos sobre su propia experiencia vivida, relacionando lo personal con lo cultural'». (Richardson, 2003: 5I2). (Blanco, 2012: 56).
} 
que lo que no hay que comprometer es el objetivo. Hay que tener claridad y percatarse de si el conocimiento es sobre el sujeto que investiga, sobre otros individuos o sobre la conjunción equilibrada de ambos, que es lo más difícil de realizar exitosamente.

La autoetnografía, por su propia naturaleza, al meterse en aguas de distintas disciplinas es interdisciplinaria o quizá solo multidisciplinaria. Al utilizarse la autoetnografía -en cualquiera de sus formas- se pretende romper con la distancia supuestamente neutral y objetiva que predominaba en la investigación social hacia los sujetos a ser conocidos. Evidentemente, la neutralidad nunca ha existido, pero la pretensión de ella y de objetividad refuerza la distancia. Esa distancia que, en efecto, muy a menudo existe en virtud de las diferencias y que es preciso tratar de borrarla a lo largo del proceso investigativo, en la medida en que se va produciendo un acercamiento entre investigadora e investigadas.

Una característica más es la de que se exponen las propias emociones y experiencias en el proceso cognoscitivo, así como en la exposición de los resultados, cosa que también estaba totalmente proscrita de la pretensión de obtener conocimientos «neutros y objetivos».

Se puede ver, entonces, que la autoetnografía ha abrevado de dos grandes fuentes. Por un lado, del feminismo y, por otro, del pensamiento de la posmodernidad. Ambos se han empeñado por décadas ya en transformar el proceso de investigación tanto como el lenguaje de la fase de comunicación de resultados. Sin embargo, una gran diferencia es que mientras la forma expositiva del feminismo tiende a ser clara y distinta, los textos posmodernos son, en general, oscuros.

No puedo dejar de pensar en lo que una vez afirmara Nietzsche: «Quien sabe que es profundo se esfuerza por ser transparente; quien quiere parecer profundo a los ojos de la multitud se esfuerza en ser oscuro. Pues la multitud estima que es profundo todo aquello cuyo fondo no logra ver» (Nietzsche, La gaya ciencia, 93).

Conocer a los seres otros o los distintos no sería autoetnografía, sino simplemente etnografía; sin embargo, el estudio de sujetos que la investigadora considera cercanos, como del propio grupo, sí lo sería. De ahí que el estudio de las mujeres artesanas o artistas, aunque pertenezcan a otras clases sociales y a otras etnias, las acerca a mí como sujeto cognoscente. No voy a 
conocer a las otras, a las diferentes, sino a nosotras las mujeres y sus diversos quehaceres artísticos dondequiera que se encuentren.

En esta medida, el trabajo que llevo a cabo de conocer al arte popular que realizan las mujeres en México y en otras partes del mundo, de acuerdo con todas las características de la autoetnografía, se inscribiría plenamente en ella. En mi proceso de trabajo se da una valoración, desde un principio, eminentemente subjetiva de los objetos que voy a estudiar y de quienes los hacen, me tienen que gustar, ser placenteros, lo cual me ha valido en más de una ocasión la etiqueta de hedonista.

De la misma manera en que se pueden expresar los gustos o disgustos, las sensaciones y sentimientos frente a lo estudiado, también es válido expresarse con ironía, manifestar la ira y las emociones tan contundentemente como se quiera. Lo cual, a la hora de la hora, es casi invariablemente censurado por los o las pares. Si se es demasiado vehemente no es aceptado en la academia, así se trate de autoetnografía.

Siempre que he estado realizando trabajo de campo he tratado a las mujeres artesanas como iguales, sin aludir a clase, raza o nación, y no tengo duda de que en la inmensa mayoría de los casos se establece una empatía, en virtud del género, que nos acerca.

Mi relato autobiográfico no está presente, pues no me ha interesado introducirlo, pero mis gustos, mi mirada, mi yo individual están ahí deliberadamente. He tratado siempre de escribir de la manera más disfrutable posible, sin pensar en ningún momento que estoy haciendo literatura. Intento que las entrevistadas se expresen tanto directamente como a través de mi voz de la forma menos tediosa que encuentro.

Por otro lado, la fotografía, estática y en movimiento, ha acompañado con frecuencia el trabajo antropológico y etnográfico desde los inicios de estos medios. Incluso el propio Bronislaw Malinowski registra a la sociedad trobriandesa por medio fotografías con la presencia del antropólogo en ellas. ${ }^{4}$

${ }^{4}$ Ver fotografías: <https://www.google.com/search?q=malinowski+trobriandeses+y+fotograf\%C3\%ADas\&rlz=IC5CHFA_enmX930 MX930\&biw=I339\&bih=738\&sxsrf=ALeKkoIy9Lg-Wyu2Vueutylagtdlkcbzlg:I6I55998927I2\&tbm=isch\&source=iu\&ictx=I\&fir=iHewHduf4QYNaM\%252C39Xro7pWcl79DM\%252C_\&vet=I\&usg=AI4_-kQipb9gAySaki4Yzxti4 PadCg5qea \&sa=X\&ved=2ahukewjBynd nkqzvAhvra6wkHz2Pal4Q9QF6BAgEEAE\#imgrc=iHewHduF4QYNaM>. 
Innumerables son quienes han utilizado este medio, además del texto escrito, para el registro de información e incontables también quienes aparecen fotografiados durante su trabajo de campo; por ejemplo, Gertrude Duby Blom (y su marido Frans Blom) aparece infinidad de veces en sus investigaciones con indígenas de la selva lacandona de México. Sin embargo, no creo que a eso se le pudiera llamar propiamente autoetnografía. ¿O sí? En mis investigaciones sobre arte popular he utilizado la fotografía, evidentemente, para documentar a las mujeres y los objetos que crean. Sin embargo, yo no aparezco casi nunca.

Es ahora cuando, al escribir este texto y reflexionar sobre el tema, me percato de que la autoetnografía que he realizado es bastante limitada, pues mi biografía explícita se halla ausente de mis textos y mi imagen también. Sin embargo, trato de que mi voz y mi mirada estén bien presentes, como dije también en cuanto a las imágenes, pues, a pesar de que las fotografías que tomo son bastante pobres, a veces no cuento con mejores y las valoro en la medida en que representan mi selección personal.

También se puede denominar autoetnografía cuando personas integrantes de un grupo social cualquiera, indígenas en el campo o adolescentes de las calles de una gran metrópoli, por ejemplo, realizan una película sobre su propia realidad. La vida de una familia ikoods (México, 1985), de Teófila Palafox, sobre la vida cotidiana en San Mateo del Mar, Oaxaca, sería uno de los primeros experimentos de esta naturaleza en México bajo la guía de Luis Lupone; y Voces de la Guerrero, que son jóvenes en situación de calle en la Ciudad de México, de Adrián Arce, Diego Rivera y Antonio Zirión (Homovidens, México, 2004) es otro ejemplo.

Mucho es ya lo obtenido en el terreno de las autoetnografías fílmicas o de las etnografías sensoriales. Particularmente interesante es el trabajo del francés Stephane Breton en Nueva Guinea y en varias otras partes del mundo, así como el que realizan en el Sensory Ethnography Lab de la Universidad de Harvard.

En cuanto al trabajo autoetnográfico audiovisual, también veo que se puede caer fácilmente del lado de la autobiografía, aunque se pretenda introducir un contexto sociohistórico, como en el caso de la película Someone to Love, de Cristina Núñez (Barcelona, 20II), que sería un relato autobio- 
gráfico de nuevo cuño, si se quiere, pero no creo que se pueda considerar autoetnografía, aunque seguramente pretende serlo.

Está por verse de qué manera puede ser fructífero el uso de los selfies, tan terriblemente populares, y que tal vez para una autoetnografía podrían ser una herramienta significativa, siempre y cuando se vaya más allá de la mera autobiografía.

Me pregunto si esto que a partir de la década de los ochenta se ha tenido a bien denominar autoetnografía, tal vez ya existía desde la década precedente y era la investigación feminista.

Así pues, si la autoetnografía representa ante todo el estudio de lo semejante, incluyendo las vivencias y las experiencias de la investigadora, todo ello narrado en un lenguaje en primera persona y lo más literario posible, en realidad, si de estudiar a las mujeres se trata, estamos hablando de una etnografía feminista. De hecho, la investigación social o humanística realizada con teoría y metodología feministas tendrá, entre otras, todas las características mencionadas.

Ahora bien, algunos de los problemas que veo en ciertas autoetnografías, como señalé y otras personas lo han hecho también, es que pueden ser demasiado autocomplacientes, demasiado autorreferenciales, tanto que el sujeto cognoscente se convierte en lo más importante del proceso de investigación. De hecho, puede verse esto en algunos textos como por ejemplo en el de Manuel Antonio Velandia que se titula «De la autobiografía a la autoetnografía como herramienta para el estudio de sí mismo» (2010), eso lo dice todo. Es probable que haya una priorización ahora en el quehacer investigativo, y en el creativo también, de un mirarse el ombligo. Por eso, quizá es preferible apostar pura y simplemente por una etnografía feminista.

Me voy a permitir compartir otra idea de Nietzsche (muy misógino, ya lo sabemos) escrita en I882, que me parece adecuada en relación con los propósitos de una autoetnografía o incluso de una etnografía feminista:

Y aún estamos lejos de que a su vez se unan al pensamiento científico las fuerzas artísticas y la sabiduría práctica de la vida, y de que se forme un sistema orgánico superior respecto al cual el sabio, el médico, el artista y el legislador, [sic] como ahora los conocemos, parezcan miserables reliquias. (Nietzsche, La gaya ciencia, 76). 


\section{ACTIVISMO EN LAS UNIVERSIDADES}

Desde hace tiempo considero que algunas académicas que ya no somos jóvenes focalizamos nuestro «activismo» en la academia. Y dije focalizar, pero no exclusivamente, pues continuamos con acciones callejeras, asistencia a los Encuentros Feministas Latinoamericanos, a los nacionales y otras actividades que utilizamos para conectarnos, para expresarnos y para difundir ideas. Ahora bien, no quiero pasar por alto el hecho de que en los últimos encuentros en los que participé sentí un cierto malestar. Las jóvenes, tan esperadas, cuya participación habíamos anhelado por mucho tiempo, llegaron mayoritariamente $y$, en cierta manera, nos hacían un tanto a un lado y nos consideraban una especie de dinosaurios. «Históricas», se nos denomina supuestamente con respeto, pero la sensación es de arrinconamiento. En décadas pasadas las jóvenes, que todavía no eran mayoría, realizaban en el seno de los encuentros sesiones solo para jóvenes, para conocerse, discutir ideas y fortalecerse, en las cuales no éramos bienvenidas. En el último Encuentro Feminista Latinoamericano y del Caribe realizado en Montevideo en 2017 se organizó una sesión para las viejas. No se le impidió el paso a las jóvenes, pero solo participó una que otra en tanto acompañante. Se ha dado una especie de segregación generacional.

Tenemos en México, y en muchas otras partes del mundo, un movimiento feminista muy activo y muy aguerrido. Las mujeres jóvenes han tomado la estafeta y se lanzan con gran cólera acumulada, como si trataran de compensar la poca actividad multitudinaria en estos años transcurridos entre los inicios del movimiento en los setenta y hoy día. El movimiento ha ido creciendo sin parar, pero la violencia contra las mujeres (feministas o no) no ha tenido tregua. De ahí, de un patriarcado rampante y un feminicidio sistemático y sistémico, surge la rabia y la cólera con la que las jóvenes se lanzan a la calle. Pero las reprimendas y la censura no se hicieron esperar. Esas no son formas, la violencia no se combate con violencia (¿no?). Salgan a la calle, pero tranquilamente, modositas y bien portadas. No es posible que la gente no se dé cuenta del significado de las acciones feministas virulentas y rabiosas.

Si el feminismo ha sido muy «bien portado» durante casi medio siglo y la violencia contra las mujeres se ha incrementado exponencialmente, quizá 
es más efectivo actuar enérgicamente para ver si así los gobiernos escuchan y toman cartas en el asunto.

Se han autodenominado feministas anarquistas aquí y ahora en México. Bueno, quizá esto no sea algo muy nuevo; el movimiento feminista desde sus orígenes se vio emparentado, inspirado, por el pensamiento anarquista. A finales del siglo xIx, por ejemplo, Emma Goldman ya unía feminismo y anarquismo. Me imagino que muy pocas de las jóvenes feministas anarquistas habrán leído a los y las clásicas del anarquismo en el mundo: los rusos del siglo xix Mijaíl Bakunin y Piotr Kropotkin, el francés Pierre Joseph Proudhon y el italiano Errico Malatesta, que ya muere en el siglo xx, igual que la avecindada en Estados Unidos, Emma Goldman. O si conocerán las luchas de Buenaventura Durruti durante la Guerra Civil Española. En México están los hermanos Flores Magón a principios del siglo xx y mujeres también las hubo: Margarita Ortega, Esther Torres y, en su momento, Juana Belén Gutiérrez de Mendoza, entre otras.

Como sea, las feministas anarquistas han llevado a cabo acciones durante 2020 muy significativas y nuevas como la okupación de la Comisión Nacional de Derechos Humanos en la Ciudad de México y otras.

Llama particularmente la atención que con referencia al movimiento feminista del presente se afirme que:

Actualmente el feminismo en México no llega a ser un movimiento social definido y visible ya que sus posturas están lejos de tener una aceptación generalizada, se han diferenciado y han dado un giro con respecto a las ideas de los primeros movimientos. (Martínez Becerra, 2019).

En efecto, un nuevo momento del movimiento feminista será diferente del precedente, pero no por ello deja de ser un movimiento social definido, bien visible y hoy mucho más numeroso que en décadas pasadas.

Otra de las cuestiones nuevas de los últimos cinco años, más o menos, son los grupos o colectivas feministas organizadas dentro de las universida-

`Ver el artículo de Merarit Viera, «La okupa feminista en México: refugio de colectividad y esperanza» <https://desinformemonos.org/la-okupa-feminista-en-mexico-refugio-decolectividad-y-esperanza/>. 
des. En el pasado prácticamente el único grupo universitario fue el Grupo Autónomo de Mujeres Univeritarias (GAMU) en la UNAM creado a finales de los años setenta. De ahí en fuera, pocos y esporádicos grupos han surgido y no es sino hasta la segunda década del siglo XXI en que aparecen en varias universidades. Es muy probable que su antecedente inmediato haya sido el movimiento \#yo soyız2 de 20I2, que surgió en la Iberoamericana, una universidad privada, y se extendió como reguero de pólvora a muchas otras de todo el país. Su principal medio de comunicación fueron las redes sociales.

Las colectivas están integradas por estudiantes (a veces alguna académica) contra el acoso y el hostigamiento sexual en el seno de la academia, esto es principalmente lo que las moviliza. No hay duda alguna de que lo que ha hecho que se organicen las jóvenes ha sido la enorme, y hasta ahora imparable, violencia. Desde el acoso cotidiano, dentro y fuera de la academia, pasando por el hostigamiento, hasta el feminicidio. La Colectiva Violetas de la FEs Aragón dijo: «QQué nuestro hartazgo los acorrale y nuestra ira los condene!». Y eso es precisamente lo que sucede, están hartas, estamos hartas, la ira es gigante.

En la UAM-X estuvieron muy activas y denunciaron abusos en diversos espacios, hasta llegar a irrumpir en sesiones del Consejo Académico incluso. Asimismo, en otras universidades como en la Unam las estudiantes se han organizado y han llevado una lucha constante y en crecimiento nuevamente, sobre todo, en contra de la violencia hacia las mujeres (Soto, en línea). Se han creado diferentes grupos, por ejemplo "Disidentas", que ha llevado a cabo diversas acciones y que se proyecta digitalmente. Las estudiantes tomaron varias facultades en el 2019 y 20 para exigir que las autoridades hicieran algo específicamente en contra de la violencia hacia las mujeres y las paralizaron por varios meses. De ahí surgen las unidades de género en la institución.

Asimismo, se organizaron docentes y alumnas para crear instancias respaldadas por las autoridades para prevenir $\mathrm{y}$ atender las denuncias de acoso y se creó, por ejemplo, en la UAM-X el Programa Cuerpos que Importan en 20II. También fue un parteaguas en la uam la instalación del Muro de De- 
nuncia del Acoso en 20I6, en donde colocaron con nombres y apellidos de los profesores y funcionarios que hostigaban sexualmente a las estudiantes. ${ }^{6}$

Con la fuerza de estos empujones en varias instituciones de educación superior se han ido creando unidades o bien mecanismos para intentar frenar la violencia de género. Ahora bien, en el caso de la UAM-X dejó de ser institucional Cuerpos que Importan, se volvió un colectivo autónomo, y se creó la Unidad de Prevención y Atención de la Violencia de Género (UPAVIG), que es institucional y opera una en cada unidad de la universidad. La institucionalización contra la autonomía ha sellado la historia del feminismo y ahora también en cuanto a las acciones contra la violencia «de género». A veces se pasa de la autonomía a la institucionalización y en otras es al revés. Se creó recientemente institucionalmente un Protocolo para la atención de la violencia de género en la Unidad Xochimilco y en las otras unidades.

Es relevante señalar que también se ha iniciado una práctica muy importante en las universidades, que es separar de sus cargos a los docentes sexistas y hostigadores. Es solo el principio, pero representa un paso adelante.

\section{A FUTURO}

Por un lado, pienso que no podemos quitar el dedo del renglón en cuanto a la creación y multiplicación de los programas, carreras, posgrados en estudios feministas. Hace años, el Doctorado en Ciencias Sociales, área de concentración Mujer y Relaciones de Género, que ya mencioné, se impartió en sedes alternas, por ejemplo en la Universidad Autónoma de Querétaro y en la Universidad Autónoma de Ciudad Juárez. Nuestro deseo era que a raíz de esa experiencia y esa formación se crearan en diversas universidades e instituciones de educación superior posgrados en género, mujeres y feminismo en distintos estados. También nos hemos pasado muchos ańos yendo a distintas ciudades grandes y pequeñas del país para dar cursos, seminarios,

${ }^{6}$ Ver la nota sobre estas y otras acciones en La que arde. <https://www.laquearde. org/20I6/o7/20/cuerpos-que-importan-portranslucido/\#: : :text=A\%2opartir\%2odel\%2O 2011\%2C\%2ola,las\%2odenuncias\%2ode\%20acoso\%2oescolar>. 
conferencias, y quiero pensar que todo ello se ha sumado para propiciar el surgimiento de esta nueva ola feminista.

Es un gran aliciente constatar que se está dando un imprescindible relevo generacional. Las feministas jóvenes se están incorporando a los programas feministas existentes ya como docentes. Asimismo, se está llevando a cabo cada vez más investigación y más actividad política feminista tanto en las calles como en el campo de la política formal. Nos percatamos que muchas de las mujeres involucradas en todo ello son egresadas de nuestros programas de posgrado de la UAM-X.

Para terminar, me gustaría citar a la escritora Isabel Allende, quien dice acertadamente:

[...] la revolución más importante del siglo xx [...] la del feminismo ha sido más profunda y duradera, afecta a la mitad de la humanidad, se ha extendido y tocado a millones de millones de personas y es la esperanza más sólida de que la civilización en que vivimos puede ser reemplazada por otra más evolucionada. (Allende, 2021: 22-23).

La utopía es lo que ha impulsado al movimiento feminista. La idea utópica de un mundo sin discriminación alguna, sin violencia alguna, con justicia, armonía y paz es, hoy por hoy, una utopía que impulsa las luchas feministas. No me refiero, desde luego, a la aspiración de una sociedad ideal e irreal o fantástica. Es la persecución, por medio de la lucha, de una sociedad más justa, igualitaria y sin violencia.

Estamos empezando la tercera década del siglo Xxi y se sigue debatiendo en el seno del feminismo en qué ola estamos. Ya no sabemos ni cuántas son. En otro trabajo me metí de lleno en la discusión de las olas y no lo voy a hacer aquí.7 Simplemente me interesa mencionar que de acuerdo con Emily Voss y hablando de Estados Unidos ella piensa que en 2012 inició la cuarta ola. En los noventa del siglo pasado la tercera y en los sesenta la segunda. La primera, según ella, empieza a principios del siglo xx. Ella sitúa justamente en la cuarta ola el resurgimiento del feminismo en las universidades y el dis-

\footnotetext{
7 Ver mi texto «El feminismo y sus olas», Zona Franca, diciembre 2020. doi <https:// doi.org/I0.35305/zf.vi28.I79>.
} 
tintivo de esta ola sería, de acuerdo con la autora, el empoderamiento de las mujeres y la interseccionalidad (Voss, en línea). Un problema que se presenta con las activistas y las pensadoras jóvenes es que creen que el pensamiento feminista nació con ellas. Decir que la interseccionalidad señala el inicio de la cuarta ola en 2012 es no darse cuenta que el concepto empezó a circular impulsado por Kimberlé Crenshaw dos décadas antes, en I99I. Lo mismo sucede con empoderamiento; no es una noción que aparezca en $2012 \mathrm{ni}$ mucho menos. El empoderamiento tiene una larga tradición, incluso dentro del marxismo, y el empoderamiento de las mujeres se pone en circulación principalmente en la década de los noventa.

Esto muestra que es imprescindible la memoria y la historia. El feminismo no empezó hoy en la mańana. Es fundamental mirar hacia atrás y reconocer los orígenes y la historia tanto del pensamiento como del movimiento feminista. De lo contrario, todos los días se intenta descubrir el hilo negro.

Es mucho lo que nos queda por caminar en esta transición hacia un modelo de universidad transformador $y$, por lo tanto, feminista, pero recordemos a aquellas mujeres que tuvieron que vestirse de hombres para poder entrar en la universidad hace no tanto tiempo. Sigamos denunciando, proponiendo y exigiendo aquellos cambios que promuevan que la universidad se convierta en un actor clave en la generación de conciencia crítica y aportes hacia un cambio social feminista. (Viadero y Gabe, en línea).

Creo que no hay duda de que nuestra labor desde la academia ha sido fructífera y que hemos contribuido (cual grano de arena) a que hoy el movimiento feminista haya levantado el vuelo como lo ha hecho. Pero sería maravilloso no tener que pensar ya en términos de lucha feminista. Sería maravilloso que ya no existiera la necesidad de ello. Sería maravilloso que se lograra, algún día, erradicar la violencia hacia las mujeres -en todas sus formas- y que existiera una igualdad, una paridad y una equidad cabal entre los géneros. Sería maravilloso, pues ya no necesitaríamos al feminismo. O como dice 
una pegatina de los Estados Unidos «Seré postfeminista cuando viva en un mundo postpatriarcal».8

\section{REFERENCIAS}

Allende, I. (202I). Mujeres del alma mía. México: Plaza y Janés.

Bartra, E. (1999). El movimiento feminista en México y su vínculo con la academia. La Ventana, Io.

Blanco, M. (20I2). Autoetnografía: una forma narrativa de generación de conocimientos. Andamios. Revista de Investigación Social, g(19), 49-74. <http://www.scielo.org.mx/scielo.php?script=sci_arttext\&pid=SI870-00632012000200004>.

Blanco, M. (2012) ¿Autobiografía o autoetnografía? Desacatos (38). <http://mastor.cl/blog/wp-content/uploads/2oI7/Io/Blanco.-Autobiografia-o-autoetnografia.-Desacatos.-num.-38.-enero-abril-2oI2-pp.-I69-I78pdf.pdf>.

Follegati Montenegro, L. (2016). Feminismo y universidad: reflexiones desde la Universidad de Chile para una educación no sexista. En Red Chilena contra la Violencia hacia las Mujeres (ed.), Educación no sexista hacia una real transformación (pp. I2I-I33). $<$ https://www.researchgate.net/publication/329923933_Feminismo_y_Universidad_de_Chile>.

Martínez Becerra, M.R. (20I9). Feminismo mexicano: la transformación de la lucha. <http://tiempouam.azc.uam.mx/articulos/feminismo-mexicano/>.

Nietzsche, F.W. (2015). La gaya ciencia. <http://www.nactecco.com/ wp-content/uploads/2015/o2/Wilhelm-Nietzsche-Friedrich-De-La-Gaya-Ciencia.pdf $>$.

Petroni, M.A. (2009). Fotografiar al indio. Un breve estudio sobre la antropología y la fotografía mexicanas. Dimensión Antropológica, 46, I83-215. <http://www.dimensionantropologica.inah. gob. $\mathrm{mx} /$ ? $\mathrm{p}=3874>$.

\footnotetext{
${ }^{8}<\ll$ I will be a post-feminist when I live in a post-patriarchal world»>.
} 
Rovetto, F. y Figueroa, N. (20I7). «Qué la universidad se pinte de feminismos» para enfrentar las violencias sexistas». Descentrada, $I(2)$. $<$ http://www.memoria.fahce.unlp.edu.ar/art_revistas/pr.7919/ pr.7919.pdf $>$.

Soto Espinosa, A. (2018). Estudiantes contra el patriarcado: las nuevas colectivas feministas en la Unam.

$<$ http://www.la-critica.org/estudiantes-contra-el-patriarcado-las-nuevas-colectivas-feministas-en-la-unam/>.

UAM (20I9). Anuario Estadistico. <https://transparencia.uam.mx/inforganos/anuarios/anuario2org/anuario_estadistico2ol9.pdf>.

UAM (2018). Rectores de la Unidad Iztapalapa. UAM. <https://www.uam. $\mathrm{mx} / \mathrm{sah} / \mathrm{pre}$-pa/temao4/gal-rizt.html>.

$\operatorname{UAM}(\mathrm{s} / \mathrm{f})$. Rectores de la UAM-X. UAM Unidad Xochimilco. <https://www. xoc.uam.mx/rectores $>$.

UAM (s/f). Rectores de la Unidad. uAM Unidad Cuajimalpa. <http:// www.cua.uam.mx/conoce-la-uam-unidad-cuajimalpa/informacion-institucional/rectores-de-la-unidad $>$.

UAM (s/f). Rectores de la Unidad Azcapotzalco. UAM. <https://www.uam. $\mathrm{mx} / \mathrm{sah} / \mathrm{pre}$-pa/temao4/gal-razc.html>.

UAM (s/f). Informes. UAM Unidad Lerma. <http://www.cua.uam.mx/ conoce-la-uam-unidad-cuajimalpa/informacion-institucional/ rectores-de-la-unidad>.

Velandia Mora, M.A. (20I0). De la autobiografía a la autoetnografía como herramienta para el estudio de sí mismo. <http://www. academia.edu/IOoI537/De_la_autobiograf\%C3\%ADa_a_la_autoetnograf\%C3\%ADa_como_herramienta_para_el_estudio_ de_s\%C3\%AD_mismo>.

Viadero Acha, María y Mugarik Gabe (20I6). Universidad transformadora y feminista. <https://www.pikaramagazine.com/2016/12/ universidad-transformadora-y-feminista/ $>$.

Voss, Emily (2020). The Rise of Feminism in College Campuses in America. <https://anchor.hope.edu/opinion/voices/the-rise-of-feminism-on-college-campuses-in-america/>. 